\title{
Unorden
}

SEKTORPROGRAM

\section{Social- och hälsoområdet}

Islands ordförandeskap i Nordiska ministerrådet 2014 
Arbetsliv

Sektorprogram för Islands ordförandeskap i Nordiska ministerrådet 2014

ISBN 978-92-893-2745-9

http://dx.doi.org/10.6027/ANP2014-725

ANP 2014:725

(C) Nordiska ministerrådet, København 2014

Design: Jette Koefoed

Omslagsfoto: Einar Ólason; ImageSelect

Fotos: Imageselect

Typsnitt: Meta LF

www.norden.org/sv/publikationer

\section{Det nordiska samarbetet}

Det nordiska samarbetet är ett av världens mest omfattande regionala samarbeten. Det omfattar Danmark, Finland, Island, Norge och Sverige samt Färöarna, Grönland och Åland.

Det nordiska samarbetet är politiskt, ekonomiskt och kulturellt förankrat och är en viktig partner i europeiskt och internationellt samarbete. Den nordiska gemenskapen arbetar för ett starkt Norden i ett starkt Europa.

Det nordiska samarbetet skall stärka nordiska och regionala intressen och värderingar i en global omvärld. Gemensamma värderingar länderna emellan bidrar till att stärka Nordens ställning som en av världens mest innovativa och konkurrenskraftiga regioner.

Nordiska ministerrådet

Ved Stranden 18

DK-1061 København K

Telefon (+45) 33960200

\section{www.norden.org}




\title{
norden
}

SEKTOR P R O G RA M

\author{
Social- och \\ hälsoområdet
}

Islands ordförandeskap i Nordiska ministerrådet 2014

\section{Innehåll}

5 Välfärd och ett vittomfattande deltagande

7 Förebyggande åtgärder

10 Kvalitet och trygghet i socialtjänst och hälsovård

14 Forskning och innovation 


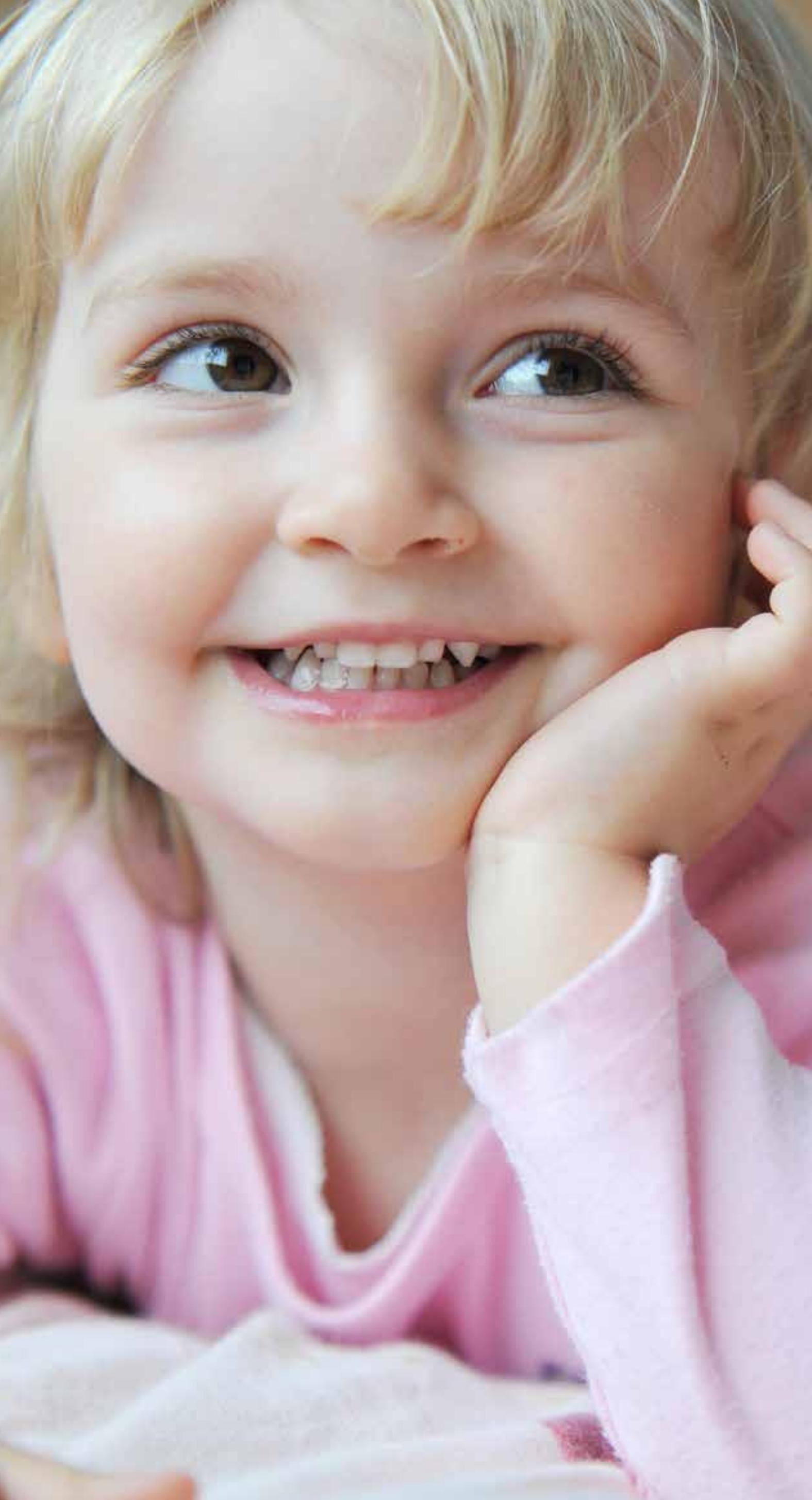




\section{Välfärd och ett vittomfattande deltagande}

Medborgarnas välfärd är en av hörnstenarna i de nordiska samhällena. Några av välfärdssamhällets viktigaste faktorer är jämlikhet, social trygghet, god hälso- och sjukvård samt socialtjänst. Demografiska förändringar, arbetslöshet och olika konsekvenser av de senaste årens ekonomiska kris har inneburit en påfrestning för de nordiska samhällenas styrka och fundament. Detta innebär utmaningar som kräver nya lösningar och mångsidigt samarbete. Några av uppgifterna är att förebygga isolering och lägga vikt vid medborgarnas medverkan, jämlikhet, sociala trygghet, en god hälso- och sjukvård samt socialtjänst.

Det nordiska samarbetet inom social- och hälsovårdspolitik under Islands ordförandeår 2014 bygger på de huvudfrågor som Nordiska ministerrådet har lagt fram för år 2013-2015 om en hållbar nordisk välfärd. Island kommer att lägga tonvikt vid att följa den strategi som social- och hälsoministrarna har satt för nordiskt samarbete på social och hälsoområdet från och med 2013. Strategien fokuserar på fyra specifika mål som skal stärka hållbar vålfärd och hälsa i Norden: Säkra social trygghet på en arbetsmarknad i ständig förändring; fokus på förebyggande insatser; höja kvalitet och säkerhet inom hälso- och sjukvård samt socialtjänst; främja innovation och forskning.

För att förbättra resultatet inom sjukvård och socialtjänst och därmed människors hälsa, sociala ställning och välbefinnande är det viktigt att ständigt arbeta för en utveckling inom dessa områden. Kontinuerligt förbättringsarbete och kvalitetsutveckling är också viktigt för att förbättra de medel och tjänster som erbjuds medborgarna. Ett målinriktat arbete för att öka välfärden kråver samspel mellan olika partner. Under ordförandeåret kommer Island att lägga tonvikt vid integrerat samråd, samarbete och samordning av lösningar inom institutioner och förvaltningsnivåer. 
I

I

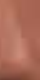

\section{9:}
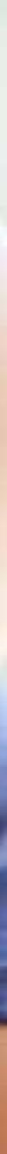


\section{Förebyggande åtgärder}

\section{Barn och familjer}

Barns välbefinnande och ett gott samspel mellan samhälle och familj är en av grundpelarna för en sund och framgångsrik samhällsutveckling. De villkor och förhållanden som barnen växer upp under i sina hem är grundläggande för deras framtid och det är därför viktigt att måna om familjernas välfärd. Under ordförandeåret kommer Island att uppmärksamma de villkor som är nödvändiga för ett familjevänligt samhälle, där alla har lika möjligheter och trygghet och omfattas av lagskyddade rättigheter. En stark familjepolitik utgör en viktig del av åtgärderna för att uppnå detta mål. Under ordförandeåret kommer Island att rikta uppmärksamhet mot familjepolitiken i Norden, bland annat kommer olika familjetypers varierande sociala ställning att studeras.

\section{Konferens}

Konferens kommer att hållas om barns välbefinnande och familjepolitik i Norden. Där kommer det bland annat olika familjetypers varierande sociala ställning att diskuteras och en presentation av huvudprinciperna i genomförandet av familjepolitiken i varje land kommer att ges. Tid: 5 september 2014. Plats: Reykjavík

\section{Sexuellt våld mot barn}

Följderna av sexuellt våld mot barn kan uttrycka sig på många olika sätt, såväl tidigt som sent i barnets liv, med sviktande hälsa och sänkt livskvalitet. Denna typ av brott begås i hela Norden men ländernas kraftfulla preventiva arbete har minskat våldets allvarliga följder. I detta sammanhang är det också på sin plats att nämna de nordiska ländernas goda samarbete på området inom Council of the Baltic Sea States under namnet Children at Risk.

Under ordförandeåret lägger Island tonvikt vid samtal och samarbete mellan de nordiska länderna om hur sexuellt våld mot barn i framtiden kan förebyggas. Man kommer även att granska hur länderna har följt bestämmelserna $\mathrm{i}$ Lanzarote konventionen och hur det är möjligt att utnyttja det nordiska samarbetet ytterligare för att stärka preventionen mot detta hot.

\section{Expertmöte}

Et expertmöte kommer hållas hvor Nordens kärnfrågor för att motverka sexuellt våld mot barn kommer särskilt att diskuteras och hur Lanzarote konventionen bäst kan följas när det gäller prevention mot detta hot.

Tid: 1 april 2014. Plats: Reykjavík 


\section{Konferens}

Konferens kommer att hållas om prevention av sexuellt våld och dess resultat i Norden. Alla erfarenheter presenteras och ett exempelprojekt med syfte att motverka sexuellt våld mot barn kommer att beskrivas. Vikt kommer att läggas vid tvärvetenskapligt samarbete, information och ökat socialt medvetande.

Tid: 2 september 2014. Plats: Reykjavík

\section{Sund livsstil}

Island kommer under ordförandeåret att lägga vikt vid livsstilens betydelse för hälsa och välbefinnande. Åtgärder som bidrar till en sund livsstil i alla livets faser kommer att uppmärksammas, till exempel hälsosam kost, regelbunden motion, sömnens betydelse, goda relationer och mindre stress i vardagen. Tonvikten läggs på de beteende som bidrar till sunda vanor och det som var och en kan göra för att förbättra sin egen hälsa och välbefinnande.

\section{Expertmöte}

Nya sätt att förbättra hälsobeteendet blir sat i fokus på ett ekspertmöte. Särskild betoning kommer att ligga på att goda vanor grundläggs tidigt men även att det aldrig är för sent att ändra livsmönster.

Tid: 11-12 september 2014. Plats: Reykjavík

\section{Psykisk hälsa}

Island lägger vikt vid ökat samråd mellan de nordiska länderna inom psykiatri och stärkandet av den psykiska hälsan. Under ordförandeskapet kommer man särskilt att måna om barn och ungdomar och arbeta målmedvetet med att stärka stödet till personer och familjer i deras närmiljö. Utbildning, rådgivning och information spelar en stor roll när det gäller att stärka människors självbild, minska ensamhet, stå med de som har utsatts för fördomar och slåss mot mobbning och våld i olika former. De nordiska länderna uppföljning av Världshälsoorganisationens handlingsplan om psykisk hälsa, WHO Mental Health action plan kommer att undersökas och hur man kan utnyttja det nordiska samarbetet ytterligare för att öka förebyggande insatser och främjandet av psykisk hälsa.

\section{Konferens}

En konferens kommer att hållas om förebyggande insatser och främjandet av psykisk hälsa, särskilt med fokus på barn och ungdomar och deras familjer.

Tid: 8 oktober 2014. Plats: Reykjavík 


\section{Expertmöte}

Ett expertmöte kommer att hållas där man särskilt kommer att diskutera Nordens kärnfrågor rörande förebyggande insatser och främjandet av psykisk hälsa och hur Världshälsoorganisationens handlingsplan för psykisk hälsa bäst kan följas.

Tid: 9 oktober 2014. Plats: Reykjavík

\section{Hälsofrämjande politik}

Medborgarnas hälsa är inte enbart en fråga för hälsovårdsmyndigheterna och hälsovården. För att uppnå resultat i folkhälsan måste hälsofrågor förankras tvärs over olika sektorer.

I Norden finns gedigen kunskap om vilka faktorer i närmiljö och planering som kan påverka hälsa och välbefinnande. Finland har målmedvetet tagit hänsyn till invånarnas hälsa i all sin policy. Hur åtgärder från olika myndigheter påverkar hälsan är en ständigt växande fråga internationellt, t.ex. hur hälsan påverkas av nya lagar, regler och förordningar.

Under ordförandeåret kommer man att granska hur Norden har arbetat med en holistisk samhällssyn för att förbättra medborgarnas hälsa och hur man kan utnyttja det nordiska samarbetet ännu bättre i detta syfte.

\section{Expertmöte}

Ekspertmöte för att särskilt diskutera de nordiska ländernas arbete med en holistisk hälsofrämjande samhällssyn kommer att hållas där målsättningen blir att länderna ska lära sig av varandras erfarenheter och undersöka om man kan kartlägga hur det nordiska samarbetet kan förstärkas på området.

Tid: 3 juni 2014. Plats: Reykjavík 


\section{Kvalitet och trygghet i socialtjänst och hälsovård}

Utvärdering av framgången inom socialtjänst och hälso- och sjukvård bygger på undersökningar där man letar efter och utvecklar nya lösningar. Kontinuerligt förbättringsarbete och kvalitetsutveckling spelar en stor roll i att förbättra de tjänster och de valmöjligheter som erbjuds. Det är angeläget att myndigheter, allmänhet och andra intresserade parter har god tillgång till information och kan följa utvecklingen i samhället och bedöma kvalitet och resultat av åtgärder och tjänster.

\section{Intresseorganisationer}

Intresseorganisationer utgör en viktig faktor när det gäller att upplysa och stötta allmänheten på många områden inom hälso- och sjukvård samt socialtjänst och de stärker på så sätt välfärden i de nordiska samhällena. Utbyte av erfarenhet och kunskap om intresseorganisationernas betydelse för välfärden i Norden och deras roll för medlemmar och samhället som helhet blir därför i fokus inom det nordiska samarbetet.

\section{Expertmo̊te}

Ett möte med representanter från intresseorganisationer och myndigheter i Norden kommer att hållas på Island och man kommer att utvärdera hur deras roll och verksamhet kan utnyttjas maximalt för att stärka Nordens välfärd.

Tid: 14 oktober 2014. Plats: Reykjavík

\section{Samordning av socialtjänst och hälsovård}

Alla de nordiska länderna har utvecklat den samhällssyn att flesta individer ska kunna bo i sitt hem oberoende av ålder, hälsotillstånd eller funktionsnedsättning. Därför har en sammanordnade tjänster för människor i deras hem aldrig varit viktigare än nu. Under Islands ordförandeskap kommer Nordens erfarenheter av samordning mellan sjukvård i hemmet och social hemtjänst att granskas, samt hur tjänsterna imötesgår individernas behov, minskar institutionsvård och om det finns ekonomiska vinster av samordning av tjänsterna.

\section{Konferens}

Konferens om samordning mellan sjukvård i hemmet och social hemtjänst i Norden kommer att hållas. Man kommer att granska ländernas resultat och vinster och vilka metoder som fungerar bäst. Man kommer att redogöra för varje lands upplägg av vård och tjänster i hemmet som syftar till att skjuta upp eller förhindra institutionsboende. Exempelprojekt från kommuner i Norden kommer att presenteras. Tid: 3 oktober. Plats: Reykjavík 


\section{Registreringsutveckling inom socialtjänsten}

Nordiska kommuner erbjuder sina invånare mångsidiga sociala tjänster och stöd. En noggrann och koordinerad registrering utgör en förutsättning för en god och kontinuerlig omvårdnad och stärker dess kvalitet och säkerhet. Island vill framhålla betydelsen av att socialtjänstens registrering samordnas mellan kommunerna när det gäller grundläggande tjänster och att den kan kopplas till information från patientjournaler vid behov.

\section{Expertmöte}

Ett möte för experter i Norden kommer att hållas, där de jämför sina erfarenheter av registrering inom socialtjänsten och studerar förebilder från andra länder.

Tid: 15 oktober 2014. Plats: Reykjavík

\section{Läkemedelsfrågor}

Under ordförandeåret kommer Island att arbeta för att stärka det nordiska samarbetet $\mathrm{i}$ läkemedelsfrågor. Särskild fokus läggs på användning av kostsamma och svårhanterliga läkemedel med målsättning att säkerställa tillgången till dessa läkemedel samtidigt som kostnaden kan hållas nere i största möjliga utsträckning. Möjligheten till gemensamma läkemedelsinköp kommer också att undersökas.

Under ordförandeåret kommer den möjliga vinsten med att inleda ett fast samarbete i Norden med koordinerade arbetsmetoder och tyngdpunkter när det gäller nya och kostsamma läkemedel att granskas.

Blicken kommer att riktas mot överanvändning och missbruk av metylfenidat och andra vanebildande läkemedel och sömnmedel vilket är ett växande och kostsamt problem i hela Norden. En jämförelse kommer att göras mellan användningen och kostnaden för metylfenidat och andra vanebildande läkemedel och de metoder som länderna använder för att motverka deras oönskade effekter.

\section{Ekspertmöter}

Möten med nordiska experter kommer hållas där man diskuterar behandling och samarbete gällande kostsamma och svårhanterliga läkemedel och undersöker möjligheten till gemensamma inköp och upphandlingar av dessa.

Tid: 5 februari och 23 april 2014. Plats: Reykjavík

Ekspertmöten om överanvändning och missbruk av metylfenidat och andra vanebildande läkemedel och sömnmedel kommer även att hållas. 
Man kommer att utreda vilken samarbetsform som lämpar sig bäst för Norden i läkemedelsfrågor.

Tid: 21 oktober 2014. Plats: Reykjavik

\section{Ryggmärgsskador}

Under ordförandeåret kommer Island särskilt att uppmärksamma de ryggmärgsskadades intressen. Islands målsättning är att det ska utarbetas en helhetsplan för att förebygga ryggmärgsskador, söka bot för själva ryggmärgsskadan och hjälpa de som har drabbats av ryggmärgsskada. Man kommer att arbeta vidare med att samla in kunskap och stödja uppbyggandet av databaser där information om forskning och forskningsresultat finns tillgänglig. Detta kommer under projektet Hållbar nordisk välfärd med målsättningen att utveckla nya lösningar.

Man kommer även att betona vikten av enighet och samarbete mellan patientföreningar i Norden.

\section{Ekspertmöte}

Ett möte med experter för att diskutera forskning och utveckling av nya metoder inom förebyggande arbete, vård och assistans för ryggmärgsskadade kommer att hållas.

Tid: 27 maj 2014. Plats: Reykjavík

\section{Översiktsrapport om ryggmärgsskador}

De främsta experterna på ryggmärgsskador i Norden och internationellt kommer att inbjudas för att utarbeta en översiktsrapport i frågan. Den kommer att handla om de ryggmärgsskadades situation på basis av den nyaste forskningen, rehabilitering och utveckling inom behandlingen av ryggmärgsskador. Man kommer dessutom att presentera vad som har gett bäst resultat i dessa frågor och lägga fram en vägledning utifrån det. 


\section{Forskning och innovation}

\section{Välfärdsteknik}

Nyskapande och utveckling av välfärdsteknik står högt på listan för i Norden. Det rör sig bland annat om lösningar för människor med särskilda behov, till exempel gällande behandling, omvårdnad, hjälpmedel, åtgärder i hemmet, träning, rehabilitering, habilitering, specialundervisning och individuellt stöd i arbetet.

Island kommer att poängtera ländernas samarbete inom välfärdstekniken där man ser möjligheter att utveckla nya idéer till lösningar som stödjer eller upprätthåller kvalitet och trygghet inom social- och hälso- och sjukvården.

\section{Konferens}

Konferens om innovationer och teknik inom välfärdstjänster kommer att hållas, där kärnfrågor, målsättningar och handlingsplaner i Norden presenteras.

Tid: 5 och 6 juni 2014. Plats: Akureyri, Island

\section{Gemensamma forskningsansökningar inom hälsovetenskap i Norden}

Tillsammans utgör de nordiska länderna en mycket starkare samarbetspartner för forskning inom hälsovetenskap än varje enskilt land. För att uppnå detta krävs en viss central samordning och utvärdering av forskningsprojekt och ansökningar till etik- och personskyddsnämnder. En värdering av en ansökan i ett av de nordiska länderna skal alltså vara giltig även i de andra nordiska länderna när det rör sig om samnordisk forskning.

Man har arbetat med detta inom nordiskt samarbete under de senaste åren och under ordförandeåret kommer Island att lägga särskild vikt vid att avsluta denna uppgift. Det kommer att ske genom stöd och främjande av det arbete som redan inletts i samarbete med Nordiska ministerrådet för utbildning och forskning. 

norden

Nordiska ministerrådet

Ved Stranden 18

DK-1061 København K

www.norden.org

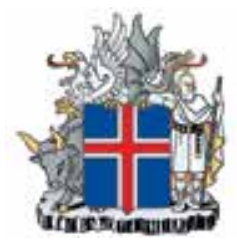

Yderligere information om Islands formandskab i Nordisk Ministerråd fås på www.norden2014.is og www.nordic2014.com.

Udenrigsministeriet Nordisk sekretariat Raudarárstígur 25 IS-105 Reykjavík Island

Telefon: +3545459900 